\title{
REASSESSING CURRENT INTERIOR DESIGN EDUCATION IN EGYPT AS A TOOL TO ACHIEVING GLOBAL COMPETENCE
}

\author{
Sarah Nabih Nasif a \\ assistant professor, interior design department, October university for modern science \\ and arts (Msa) ,cairo (11511), Egypt.
}

\begin{abstract}
:
By the recent focus of the whole world to achieving the sustainable design goals (SD goals) as a part of a better world in 2030, Countries involved (Egypt being one) have already implemented their action plans in all disciplines toward achieving their common global vision. And here comes the question: What is the extent of upgrading that has taken place since then especially in the Egyptian Higher educational sector? And more specifically in interior design education in Egypt? Is interior design education going in the right direction rightfully corresponding the global vision toward global competence? .The research assumes an outdated interior design program in Egypt, unable to contribute to the global vision toward sustainability by lacking exposing important Design approaches that can contribute to that ( E.g : Sustainable design, Inclusive design) and artificial intelligence as the new tomorrow resulting in globally incompetent students as well.

This research aims to re-evaluate the current interior design program applied and its extent of correspondence to global vision by using the analytical comparative method .and the results confirmed the research hypothesis where some recommendations will be brought up.
\end{abstract}

KEYWORDS:

Interior design education, Egypt, Global competence, Sustainable development goals.

\section{INTRODUCTION:}

There is no doubt that the world's needs are constantly changing as solutions to global problems that arise constantly. The world is in a constant thirst to search for solutions for a decent life for humans. In this context, the role of international organizations appear in trying to set goals for a better life for people, On top of all, "The united nations" that adopted an agenda for sustainable goals till 2030 in action since 2015 through main 17 sustainable goals that have already been taken in consideration in a lot of countries all over the world and have started included it in all their plans.

Quality of education being one of those goals ( Goal 4 ), is already being kept in consideration, but not highlighted enough as an influencing factor in achieving sustainable 
development(James \& Card, 2012) in addition to being a tool to achieving Global competence through our fast changing world where relevant learning should be offered as a response to those new demands and opportunities (Gardner, 2007, Reimers, 2009, Stewart, 2007).And here come the important questions ,to what extent is "Interior design education" in Egypt covering all those futuristic needs ? .To what extent are the current curriculums Suitable for equipping efficient students (globally competent ) and to what extent does the current education offered in the interior education field in Egypt help in achieving those future sustainable goals? .

\section{RESEARCH PROBLEM:}

Lack of constant evaluation to interior design programs regionally and it's correspondence to global future vision and an unknown level of education received by students, ignoring Education importance in achieving globally competent students.

\section{RESEARCH HYPOTHESIS:}

- An outdated interior design program in Egypt that doesn't conform to the world's needs and its future vision generating un competent students globally.

- A clear deficiency in teaching the design concepts that helps in achieving sustainability and SDG goals in general towards the global vision.

- A clear gap between being familiar with different design approaches (sustainability as an example) and how to apply it practically in different interior design projects efficiently. - The negative impact of an educational system that is not compatible with the society needs and global future vision.

\section{RESEARCH AIM:}

- Re-evaluating current interior design educational system and to what extent it serves future vision towards sustainability and preparing globally competent students.

\section{RESEARCH IMPORTANCE:}

- Highlighting the importance of education in preparing interior designers that are capable of achieving future global vision toward sustainability by fighting future challenges and keeping pace with global macro trends.

- Determining the design approaches that needs to be included in interior design curriculum to achieve the SD goals and prepare globally competent students.

- evaluating the current status of those design approaches and their degree of implementation in interior design programs 2021(In Egypt).

\section{RESEARCH METHODOLOGY:}

The research uses the analytical - comparative method, by analyzing the current data available regarding interior design education in Egypt and compare it with what is being 
implemented in different educational systems around the world to get an accurate evaluation.

\section{RESEARCH STRUCTURE}

The research is divided in to 3 main sections other than conclusion and researcher recommendation as follow:

Table (1) - Research structure and content (Researcher 2021)

\section{Global competence and education}

- In this section the meaning of Global competence is exposed, highlighting the importance of education in achieving it and preparing global competent students through achieving SDG goals as a tool.

2 Global competence achievement through interior design approaches

- In this section SDG goals are analyzed to conclude design approaches compatible with the future global vision.

3 Evaluating current interior design program in Egypt

- In this section, an evaluation to the current interior design program is done using the analytical-comparative method, by analyzing to what extent are the concluded design approaches (from the previous section ) immersed in the current curriculum as well as comparing it's status with what has been already implanted all over the world in the same.

\section{Conclusion \\ 5 Recommendations}

\section{GLOBAL COMPTENCE AND EDUCATION}

To understand what does it take to have globally competent students and what is the role of education system in achieving this, a deep understanding for The word "Global competence" is required. In this regard, Several definitions were out there .One of the most prominent is the one described by Mansilla and Jackson (2011), where it described global competence as "a human ability and attitude to comprehend and act on matters of global significance, and it involves the knowledge and skills needed for surviving in the 21st century. Another older definition by National Education Association (NEA, 2010) described it as knowledge and understanding of international issues, ability to learn and work with others from linguistically and culturally diverse backgrounds and skills to function in an interdependent world. Both definitions confirm one thing is that the degree of competence is measured by to what degree is the person aware of global issues and has the ability to deal with it each in his profession. 
Talking about preparing future global competent interior designers, means that the interior designer must be aware of all global trends, always updated and has the ability to use this knowledge practically and not only theoretically which would definitely start with the education system. This conclusion is confirmed as well by several researchers who tried to classify the characteristics of a globally competent student throughout the years. Mansilla and Jackson (2011) for instance summarized the core characteristics as the ability to investigate the world beyond their immediate environment, recognize perspectives of others as their own, Communicate ideas effectively with diverse audience and take action to improve conditions. Longview foundation in the year 2008 identified the most important characteristic as having the curiosity about world's history, geography, cultures, environmental and economic systems, and current international issues. Both identified characteristics lead us to one final conclusion is that to be global competent one should have the knowledge to global trends, the curiosity to always knowing more, and not only that but taking an action for a change.

In this regard OECD (2018) identified Global competence dimensions as having the skills to take action for collective wellbeing and sustainable development as one of the main pillars of global competence as per fig (1).

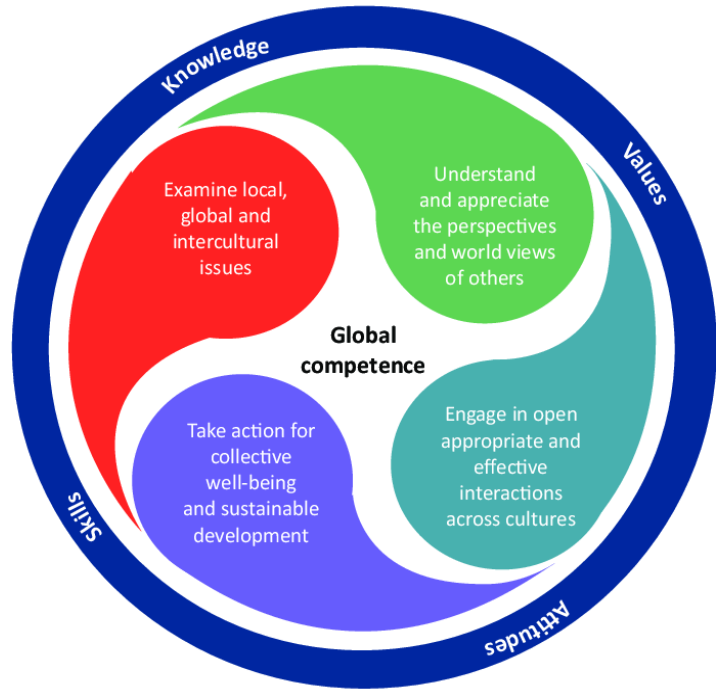

Fig (1) - The dimensions of global competence. (Source: Ramos, G. \& Schleicher, A., 2018)

This leads to another result is that there is definitely a direct link between preparing global competent students and having enough knowledge about the future vision and the sustainable design goals assigned to be full filled by 2030 and not just the knowledge, but the capability to practice it, in case of interior design major, doing applicable design projects that can help in achieving the SD goals and regarding the education system, offering updated content that corresponds those needs (Researcher 2021). 
And here comes the search for an answer to one of the research most important questions, to what extent does the current interior design program corresponds the future global vision?.

To do this, determining topics of priorities that are supposed to be in interior design program according to SD goals is analyzed

\section{GLOBAL COMPENCE ACHIEVEMENT THROUGH INTERIOR DESIGN APPROACHES}

Since there is a direct relation between global competence and SD goals, Analyzing design concepts related to SD goals is a must for an accurate evaluation of the current state of Interior design programs and the degree of correspondence to future vision.

The issue in general is not new at all, Education for sustainable development or the inclusion of key sustainability issues in all types of teaching and learning, has been supported and promoted over the last decades by global frameworks such as the United Nations and the UNESCO when the year 2005 specifically marked Nations' Decade of Education for Sustainable Development and the Global Action Program on Education for Sustainable Development (post-2014), both led by the United Nations Educational, Scientific and Cultural Organization (UNESCO) (Buckler \& Creech, 2014; UNESCO, 2014). Education system in itself and higher educational institutions with no doubt can make a significant impact in the advancement of sustainable development as they take on various roles and responsibilities. Some of these include education for a sustainable society (James \& Card, 2012) but still what does the interior design educational system has reached in this aspect especially in Egypt is not clear. To do this SD goals has to be deeply analyzed and translated to design tools and strategies and test to what extent does current interior design curriculums covers it.

\subsection{SD GOALS ANALYSIS}




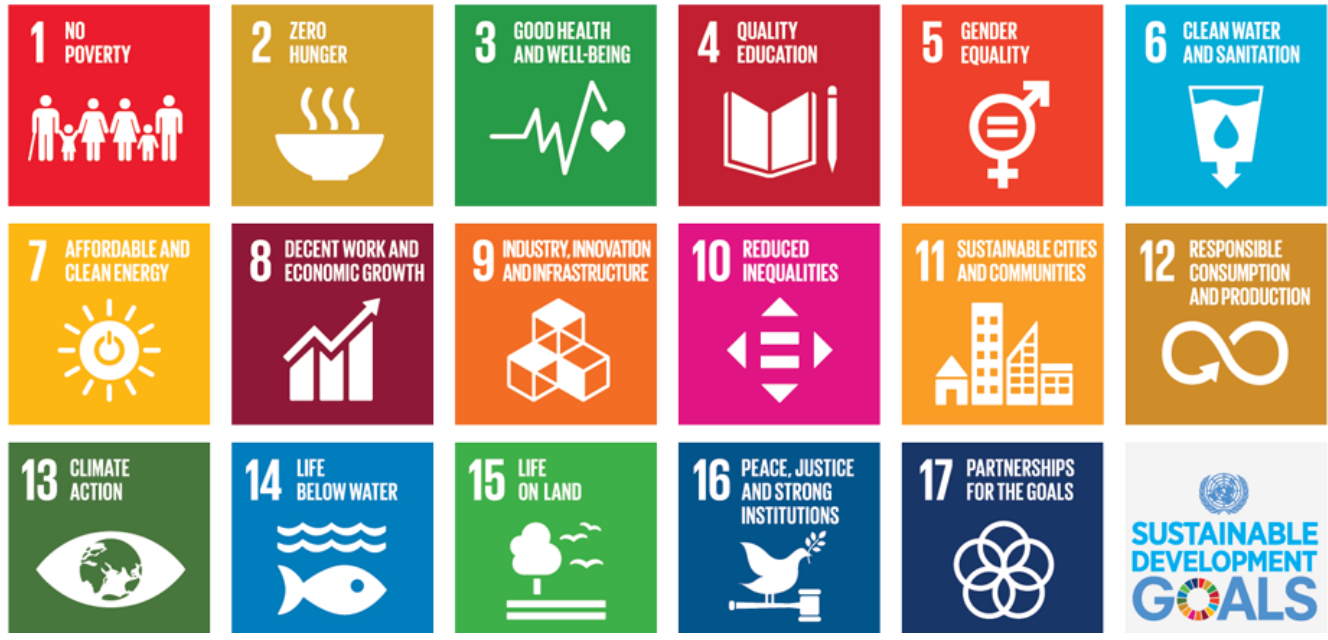

fig (2)- Sustainable development goal ( source : https://en.unesco.org)

By deeply analyzing the SD goals, it's clear that most of the goals showed in (Fig 2 ) can be categorized in to two main directions when linked with designed trends as shown in table (1):

Table (2) - Analysis of SD goals trends and design trend related - By researcher (2021)

\begin{tabular}{|l|l|l|}
\hline \multirow{4}{*}{$\begin{array}{c}\text { SD Goals } \\
\text { related }\end{array}$} & Goal 1 (indirectly linked) & Goal 5 \\
\cline { 2 - 3 } & Goal 3 (indirectly linked) & Goal 10 \\
\cline { 2 - 2 } & Goal 7 (directly linked) & Goal 16 \\
\cline { 2 - 2 } & Goal 11 (directly linked) & \\
\cline { 2 - 3 } & Goal 13 (directly linked) & \\
\cline { 2 - 3 } & Goal 15 (directly linked) & \\
\hline $\begin{array}{l}\text { Design } \\
\begin{array}{l}\text { approach } \\
\text { related }\end{array}\end{array}$ & Sustainable design & Inclusive design \\
\hline
\end{tabular}

Six out of the seventeen goals with the percentage of (35.2\%) can be directly achieved through right practice of sustainable design which is not a new topic at all and has been around since the 1970s. Three goals out of 17 with a percentage of (17.6\%) are fully dedicated to creating equality and justice in society which can be translated to the importance of teaching two main design approaches in interior design program which are Sustainable design and inclusive design (Researcher 2021).

By covering those two design approaches in the educational system ,52.8\% of Sustainable goals can be achieved starting by education, which is also a goal in itself translated as partnership for the goals (Goal 17) by using education as a tool to achieving sustainability in addition to achieving (Goal 4) which is a quality education that can be surly achieved through presenting educational 
content up-to-date and by this, covering 11 goals out of 15 goals ( excluding goal number 2 and 14) as they are not related to design directly or indirectly with a percentage of $(73.3) \%$ in total . By this, it can be concluded that teaching sustainable design and inclusive design in interior design programs are crucial for a global competent curriculum that goes with the future vision(Researcher 2021).

In addition to this, it's worth mentioning that Global trends have to be kept in consideration as part of Global competence achievement as well. In this regard, it's a well-known fact the digital transformation in general and Artificial intelligence in specific is in the top of all forecasting trend lists and cannot be neglected at all. Studies about to what extent Artificial intelligence can help in achieving sustainable development goals has begun to surface already. An analytical study done by a group of researchers (Ricardo Vinuesa1, Hossein Azizpour, Iolanda Leite,et2020) proved that Artificial intelligence may act as an enabler on 128 targets (76\%) across all SDGs by the help of technology which can help in overcoming several challenges and limitations, however there is an expected negative impact with a percentage of (34\%) which is majorly attached to not being able to reach a certain segment of society, whom did not had the opportunity to receive the sufficient type of education and don't enjoy the best economic conditions which can as a result cause a kind of inequality against inclusion concept as one of the SD goals, still if provided to all, it initially proved having a positive impact on several aspects toward sustainability.

Whatever the percentage is, it cannot be neglected that Artificial intelligence is dominating our world quickly and worries started arising regarding future Jobs and if Artificial intelligence will really cause some jobs to disappear completely. In fact, Several old forecasts already suggested that artificial intelligence is likely to eliminate almost half of present jobs by 2025 , resulting in massive unemployment (Rutkin, 2013) . Luckily enough, it is being almost assured that most of the creative industries won't be replaced easily at least not in the near future which means that we still have the opportunity to get prepared to this new revolution .Being prepared to face the new changes will help in adopting to the new digital world and it can even get one prepared to new type of jobs that could take over in the future.

After raising the issue, it can be concluded that, the most three important areas that should be already included in the education system by now can be summarized as Sustainable design , Inclusive design and Artificial intelligence (Researcher2021). And the question now is to what extent does the current interior design programs in Egypt cover those three ?.

\section{EVALUATING CURRENT INTERIOR DESIGN PROGRAM IN EGYPT}

The evaluation will be based on the (analytical - comparative method) to measure the extent of immersion to those approaches in the current Interior design program.

The analytical method: By analyzing what has already been implanted and the state currently and get a conclusion.

The comparative method: by comparing this conclusion to the current state globally to have an accurate evaluation of interior design programs offered in Egypt. 


\subsection{REGARDING SUSTAINABLE DESIGN:}

\subsubsection{ANALYTICAL METHOD}

The topic of integrating Sustainable design in the educational system generally and design curriculums specifically has been around for the longest time. A lot of researches have insisted that all starts with education and to achieve real sustainability, it has to start with it. White Myer (2007: p. 16) stated, "Education more than anything else is what will push green design into mainstream". Higher education remains the foundation from which a sustainable society can grow. . Gould (2002: p.3) argued "Schools of architecture, interior design and engineering should rewrite their mission statements, hire and tenure environmental professionals as teachers. In 2006, integrating sustainable design in under graduate curriculum was issued (Stieg 2006). It has been almost 20 years that the topic has been highlighted. But are there any progresses or real applications or just theories?

In Egypt a Study done by Rasha el zeiny in the year 2012 trying to analyze the status of sustainable design in interior design programs proved that integrating sustainability are still theories not applied in all governmental faculties teaching interior design. It has been almost 10 years and the integration of sustainability is still confined to graduation projects only and not in all faculties which makes it (when found) considered institutional and personal diligence (from the instructor's side) (Researcher 2021).

The question is: Is it lack of knowledge with the issue from the instructor's side? Is it the inability to put sustainability rules into real applications within interior design projects and going beyond the theoretical part? .

As an answer to those questions, on a global level blaming educators for this have always been there ( Fischer, 2007; Reimers, 2009) Teaching content without teaching students how to use it in a creative way is another issue exposed for the longest time now (Shari Becker , 2012).

\section{.3.12 .COMPERATIVE METHOD}

To try and get an accurate evaluation to the degree of implementation and the degree of integration to sustainability in interior design curriculum on a global level is not as easy as it seems to be, but hints are there. A Study done in 2008 by Tommy J.crane concluded that sustainable design is integrated in a way or another but not particularly as a separate unit course. Still, unfortunately studies prove that interior design students do not have a deep understanding of sustainable design and they usually connect it to technological aspects only ( Segalàs et al. 2010).

The fact is, there are several approaches out there that can help in achieving sustainability indirectly (Biophilic design to mention one). Are those approaches even considered in the entire interior design curriculum? In Egypt, those approaches are kept to students' choice of graduation project, which means that by finishing the entire program, Students may not 
be exposed to many important topics and design approaches which will result in globally incompetent students and will as a result affect achieving the Globe's future vision toward sustainability (Researcher 2021).

By comparing the current state inside Egypt and outside, the main gap relies in Instructors' capabilities as well. Foreigner instructors definitely have a better and deeper knowledge of sustainability as many of them enroll in CIDA accredited programs or leed accredited professional and though this is still a small reflection of the deep wide dimensions of sustainability yet it's better than not being exposed to it at all .On the other hand, a study showed that most Egyptian instructors get their knowledge about sustainability either through internet Browsing with $55 \%$, related books and scientific papers with a percentage of $34 \%$ and the final $8 \%$ attend related conferences or supervise postgraduate thesis (Rasha, 2012) .

By analyzing the previous data (using the analytical and comparative method), it can be concluded that ( Researcher 2021):

- There are individual attempts and interest from some interior design private educational institutions to include sustainability in their curricula, but it is still timidly implemented and not directly as a separate unit course or even being given good portion in other unit courses but in some of the graduation projects and the portion generally depends on instructor's knowledge about the matter (still in 2021). .

- there is still no deep understanding for the meaning of sustainability and ways of implementation in interior design projects both from the instructors as well as student side in Egypt.

- Lack of enough research regarding ways of implementing sustainable design in interior design programs since the topic first arose in an official way in 2005 regarding it's important within the education sector till today in 2021 confirms that there is a kind of permanent evasion from it though it's still one of the most talked about topic theoretically and it's the main future global vision.

- The interior design program is outdated to a great extent and the little personal and private institutional contribution found won't help in achieving the future global vision in the specified time frame.

\subsection{INCLUSIVE DESIGN}

Inclusivity is another topic that has been around for the longest time as a tool to achieving social justice .In design world, it is no less. Whatever it is a product design or an interior space or any type of design, at the end of the day it has to ensure that it covers all user needs regardless of their gender, race or any other factor and not making the user feel his indifference as well. 
Ostroff (2001) explains it as an integrated design approach to design products, buildings and urban for all people rather than creating special design solutions for people with disabilities, elderly people, children or pregnant women and here can be the real challenge to designers. The importance of this topic relies in it doing with user needs mainly which is supposed to be the main target of any interior designer. By analyzing the sustainable development goals, it's evident that the current call is for gender equality and creating justice, where design can be one of the most important tools to achieving it

Discussing its implementation in the educational system was there as well since 2001 (Tepfer, 2001). Almost 20 years since then, the question it to what extent is it evolved in interior design curriculums in Egypt? The evaluation will take place with the same methodology (Analytical- comparative method)

\subsubsection{ANALYTICAL METHOD}

By scanning the research engines regarding implementing inclusive design in curriculums and its importance in Egypt there is zero researches on the matter, which confirms a clear neglectance for the topic importance within interior design education in Egypt. (Researcher 2021). On the contrary, there are quite a few researches regarding improving the education system generally and trying to present an inclusive education to students focusing on trying to offer equal opportunities of education to students regardless of their difference both in schools and higher education, but no researches on its implementation in curriculums and especially interior design ones as a design approach. (Researcher 2021).

Regarding implementation, it's in the same state as sustainable design, both of which are limited to graduation projects (and left to students' choice of project and design approach ), still there are a myriad number of master and PhD thesis Focusing on sustainability and a fewer number regarding applying inclusive design in different interior spaces (Researcher 2021).

\section{2 .COMPERATIVE METHOD}

Efforts for including inclusive design in curriculums of several disciplines, interior design being one of them took place in several European countries since forever ( presier,2003).

A study done by Yasemin in 2006 as well is quite enough to prove that there are actual implementations of inclusive design in education. This study gathered case studies from several universities teaching inclusive design all over the world though the strategy of implementation varies from one country to another. In some universities, it's only offered as an elective course or in the master program. While in others, it's integrated with in the whole program. (Yasemin2006)

By analyzing the previous data (using the analytical and comparative method), it can be concluded that (Researcher 2021): 
-Various strategies of implementation to inclusive design worldwide proves that there is still no common agreement on the optimum way of teaching inclusive design and they are still trials, kept to the institution or the instructor preference.

- There is a gap in including inclusive design by comparing what's implemented in Egypt and what has been implemented around the world though it still did not reach its optimum implementation.

\subsection{ARTIFICIAL INTELLIGENCE}

Artificial intelligence is the new tomorrow without a doubt. Preparing Global competent students will be definitely measured according to what extent they have the enough knowledge and practice in the matter. The world is fully aware of it and as per studies the Global Artificial Intelligence in Education Market is forecast to grow with a percentage of $47 \%$ from the year 2018 to the year 2023 (Research And Markets.com) and is yet to grow.

\subsubsection{ANALYTICAL METHOD}

In Egypt, Some Initiatives have already started taking action through a but still on a very limited scale .In one of the top private universities in Egypt introductory workshops and awareness campaigns on the meaning of Al theoretically was introduced to both staff and students (Researcher 2021).

In the educational field, integrating intelligence in education is limited to some e-learning interfaces and correcting exams with the form of (MCQ) which is still not considered the maximum of intelligence application, yet one of the lowest ( simplest ) type of integration which can be considered even smart more than intelligent known as ( the supervised learning ) . Its methodology is based on the machine being given a certain input and being taught to respond a certain way accordingly (Vladimir,2017).

\subsubsection{COMPERATIVE METHOD}

On a Worldly scale, Artificial intelligence application has taken other forms, it's still considered in its early stages abroad, yet there are other form of applications that took place and can be considered intelligent. e.g. (Application of virtual reality).

Virtual reality can be considered a type of intelligence as well. Based on creating artificial environment based on Interaction, Immersion and Imagination (Burdea, G.; Coiffet,2003) ,it can be categorized as "Reinforcement learning" type of $\mathrm{Al}$, which is a higher level of intelligence compared to ( the supervised learning type ) depending on the machine being trained to take the decisions ( the closest in human mind ).

Myriad examples of VR applications are there especially in military training, automotive and aerospace design, medical (surgery, dental, and for phobia \& autism treatment in addition entertainment (Hailu Gebretsadik, Teklemariam,et 2014). It is also used in the education of students with special needs (Dorota, Tomasz, et.,2019). 
In Design education, virtual reality is more associated with product design than more than any other field, where VR is used to have an initial feedback about the product design .In interior design education, It was mostly translated as $3 \mathrm{~d}$ application teaching used in producing $3 d$ shots closest to reality(e.g:3d max.), but this is still not considered the accurate meaning of VR.

The fact is there are still no clear immersion for VR in teaching interior design till now, though the fact has been raised for years. A study done in 2014 recommended the importance of integrating VR in interior design curriculums to be globally relevant (Hailu Gebretsadik, Teklemariam,et 2014). It has been seven years since then and the growth of application still doesn't match the future global vision.

\section{CONCLUSION}

Based on all the previous, it can be concluded that ( Researcher 2021):

\section{Regarding interior design programs offered in Egypt:}

- Interior design programs offered in Egypt has still a long way to go. Though there are still undeniable efforts from some institutions to improving the content (especially in private institutions), still the rate of improvement doesn't match the future global vision timeline.

- Avery slow development throughout the years (Regarding updating interior design program and immersing necessary up-to-date design approaches), in addition to lack of researches that prove constant evaluation to the curriculum ( which is essential to check if we are going in the right direction ), by scanning the research found, it's evident that there is only one research done in 2012 in Egypt trying to assess interior design program since the importance of the matter was first issued in 2005 which proves mmarginalizing the importance of the educational stage in achieving future vision for various reasons .

- Design approaches that has the priority to be focused on toward sustainable development goals are identified as (Sustainable design and inclusive design) .

- Sustainable design with all sub-design approaches that can help in achieving sustainability aren't imbedded enough the interior design program though the topic has been raised for the longest time now. It's implementation is often confined to graduation projects (Which is the students' choice), which results in students not being exposed to all updated design approaches resulting in globally incompetent students same with inclusive design .

- The focus on inclusive design in interior design curriculum in Egypt is even weaker than sustainable design and a framework to ways of implementation should already take place. - Artificial intelligence implementation in in interior design major and its impact on the industry should be kept in mind for global competent interior design program design and students being it the main approach ruling the future.

\section{Regarding instructors and students:}


- A clear issue in deep understanding of those design approaches from the student's side which means an issue from the instructor side as well.

\section{RECOMENDATIONS:}

- Re-considering the interior design program content in Egypt and update it to be globally competent, by trying to immerse those design approaches in the curriculum from early stages for the best outcome.

- Benefit from the limited global expertise in applying those design approaches in their programs, evaluate them and choose the best option that fit.

- Improving Instructors 'performance and knowledge by providing workshops, conferences, programs (to be globally certified) and provide them the enough time to upgrade themselves for better education quality (as a result).

- Start from now considering the evolution artificial intelligence can cause in the industry and start preparing both staff and students with in the education system which will automatically produce globally competent staff and students (up-to-date) .

\section{REFRENCES:}

BUCKLER, C. AND CREECH, H. (2014). Shaping the future we want: UN Decade of Education for Sustainable Development; final report. UNESCO.

BURDEA, G.; COIFFET, P (2003). Virtual reality technology; wiley: hoboken, nj, usa DOROTA, TOMASZ, SŁAWOMIR WIAK ET., (2019) "Virtual Reality and Its Applications in Education: Survey"- Information-10,318.Retrived from : https://www.mdpi.com/20782489/10/10/318

FISCHER, K. (2007). Flat world lessons for real-world students. Chronicle of Higher Education. Retrieved from http://chronicle.com

GARDNER, H. (2009). Five minds for the future. Boston: Harvard Business School Press.

GOULD, K.L. (2002). Teaching green: Design with values. Retrieved from: MetropolisMag.com Web site (March 7, 2007).

HAILU GEBRETSADIK TEKLEMARIAM (2014)“ application of vr technology in design education- international conference on engineering and product design education 4 \& 5 September 2014, university of twente, the netherlands. Retrived from: https://www.researchgate.net/publication/271847160_Application_of_VR_Technology_i n_Design_Education. 
JAMES, M., \& CARD, K. (2012). Factors contributing to institutions achieving environmental sustainability. International Journal of Sustainability in Higher Education, 13(2), 166-176.

LONGVIEW FOUNDATION. (2008): The globally competent teaching continuum. Retrieved from: http://www.learnnc.org/lp/editions/global-continuum/ https://www.oecd.org/education/Global-competency-for-an-inclusive-world.pdf MANSILLA, V. B., \& JACKSON, A. (2011). "Educating for global competence: Preparing our youth to engage the world. New York: Council of Chief State School Officers"EdSteps Initiative \& Asia Society Partnership for Global Learning.

https://www.nea.org/

https://www.oecd-ilibrary.org/education/education-at-a-glance-2018_eag-2018-en

OSTROFF,E. (2001), Preparing and Recruiting Designers for An Inclusive Society, Proceedings of Inclusion by Design, Montreal,. Retrieved from http://www.adaptivenvironments.com.htm. (October 7, 2004)

PREISER, W. (2003), Inclusiveness through Universal Design Feedback and Evaluation, Education and Evaluation - Resources and Methods at Student Level, Proceedings of Include 2003, Royal College of Art, London.

RAMOS, G. \& SCHLEICHER, A. ( 2018) " Preparing out youth for and inclusive and sustainable world: The OECD PISA global competence framework"- viewed 04 March 2019, from https://www.oecd.org/education/Global-competency-for-an-inclusiveworld.pdf.

RASHA MAHMOUD ALI EL- ZEINY (2012) "Sustainability in the Education of Interior Designers in Egypt" Procedia - Social and Behavioral Sciences 38122 - 131.

REIMERS, F. (2009). "Global competency" is imperative for global success. Chronicle of Higher Education, 55(21), A29.

RICARDO VINUESA, HOSSEIN AZIZPOUR, IOLANDA LEITE, ET (2020) : The role of artificial intelligence in achieving the Sustainable Development Goals-nature communication retrived from :

https://www.researchgate.net/publication/338554769_The_role_of_artificial_intelligence _in_achieving_the_Sustainable_Development_Goals.

RUTKIN, A. H. (2013) Report suggests nearly half of u.s. jobs are vulnerable to computerization. - MIT Technology Review. Retrieved from:, https://www.technologyreview Com/s/519241/report-suggests-nearly-half-of-us-jobs-arevulnerable-to- computerization (August 18, 2016). 
SEGALAS, J., FERRER-BALAS, D. AND MULDER, K.F. (2010), "What do engineering students learn in sustainability courses? The effect of pedagogical approach", Journal of Cleaner Production, Vol. 18 No. 3, pp. 275-284.

STEWART, V. (2007): Becoming citizens of the world. Educational Leadership, 64(7), 8-14.

STIEG, C. (2006): The sustainability gap. Journal of Interior Design, 32 (1), vii - xxi.

TEPFER, F. (2001): Educational Environments: From Compliance to Inclusion, chapter in Universal Design Handbook, Preiser, W.F.E. and Ostroff, E. (eds.), McGraw-Hill, New York, pp. 46.1- 46.9.

VLADIMIR NASTESKI (2017), : An overview of the supervised machine learning methods . Retrieved from: https://www.researchgate.net/publication/328146111

WHITE MYER, D. (2007): The road to green. Perspective, winter, 9-19.

YASEMIN AFACAN (2006): integrating universal design into the main Stream of architectural design education- 1st International CIB Endorsed METU Postgraduate Conference Built Environment \& Information Technologies. 